\title{
THE CENTRILOBULAR FORM OF HYPERTROPHIC EMPHYSEMA AND ITS RELATION TO CHRONIC BRONCHITIS
}

\author{
BY \\ J. G. LEOPOLD AND J. GOUGH \\ From the Department of Pathology and Bacteriology, Welsh National School of Medicine, Cardiff
}

(RECEIVED FOR PUBLICATION MARCH 25, 1957)

The pathogenesis of hypartrophic, i.e., large lung, emphysema is unsettled, although the postulate of Laennec (1819) that it is due to partial bronchial obstruction remains widely held. Emphysematous lungs, however, show a diversity of macroscopic appearances which can be clearly seen in the paper-mounted whole lung sections used in the present study. It seems possible that the pathogenesis is not the same in all types. A variety of emphysema which involves the central tissue of the lung lobules was described by Villemin in 1866 but has, it seems, been subsequently neglected until one of us commented on this centrilobular form, having recognized it in large sections (Gough, 1952). Using the same technique McLean (1956) confirmed and extended Gough's findings. The centrilobular form is a common pattern occurring in over half of the 140 cases of hypertrophic emphysema which we have studied. The number of lobules affected varies from case to case, often amounting to the majority. The centrilobular change is to be distinguished from the other common pattern of hypertrophic emphysema which, rather than affecting the lobules individually, involves the lung as a whole and is referred to as generalized emphysema. In it there is a relatively uniform enlargement of air spaces diffusely throughout the lung. We have investigated these two different anatomical forms to determine whether they have a different pathogenesis.

Severe disability due to dyspnoea is particularly prone to be associated with centrilobular emphysema, and death commonly follows from pulmonary infection or congestive cardiac failure.

The present work is an account of the anatomy and pathogenesis of the centrilobular form contrasting it with the generalized form. Serial histological sections have been used to study the emphysematous spaces and their connexions with the bronchial tree. The centrilobular lesion appears to be a complication of generalized emphysema and is due to an extension of bronchial inflammation to the respiratory bronchioles with the result that some of these become damaged and greatly distended. It may be questioned whether the term emphysema should be applied to dilatation of respiratory bronchioles, but this is quite justified, because in so-called "vesicular" emphysema dilatation is by no means restricted to the alveoli but also affects structures bearing alveoli. It is convenient to use the definition of Heppleston (1953) to include under the term emphysema dilatations involving all respiratory passages which bear alveoli. Those describing the condition may not always have recognized that spaces they refer to as emphysema are respiratory bronchioles. Centrilobular emphysema is a condition in which respiratory bronchioles are especially affected.

\section{Material ANd Methods}

One hundred and forty examples of hypertrophic emphysema from the general population were examined post-mortem. All but ten were males. One lung from each necropsy was kept uncut and fixed by expansion with $10 \%$ formalin- $5 \%$ sodium acetate infused under low pressure into the main bronchus. After fixation, the expanded lungs were all treated by the Gough and Wentworth technique and paper-mounted entire lung sections prepared. From the pattern of emphysema in the fixed inflated lung or in its large section, or in both these preparations, the material was differentiated into two groups. In one group were placed lungs with only generalized emphysema ; in the other, lungs with generalized plus centrilobular changes. Available for comparison were a large number of normal lungs of all ages up to 85 years.

Blocks of tissue for serial histological sections were selected from the inflated lungs of 24 of the cases showing centrilobular emphysema. It was found inconvenient to examine very large emphysematous spaces in serial sections, so spaces not larger than approximately $6 \mathrm{~mm}$. in diameter were included in the tissues chosen. In each case several blocks were sectioned. The tissue was vacuum-embedded in paraffin, cut in $20 \mu$ sections, and stained with haematoxylin and eosin. These sections demonstrated the 
anatomy of the emphysematous spaces and their connexions with the bronchi in 90 individual centrilobular lesions. The bronchiolar connexions to the centrilobular spaces were compared in calibre with normal terminal bronchioles, which are the narrowest passages in the lung. For control, 20 systems of the respiratory structure, from terminal bronchiole to alveolar duct, from five normal adult lungs fixed in expansion were examined in serial sections.

Material from the emphysematous left upper lobes of two cases of congenital lobar emphysema, aged 3 and $5 \frac{1}{2}$ weeks respectively, was also examined in serial histological sections, as these have a bearing on our interpretation of the pathogenesis of emphysema.

\section{FINDINGS}

In 65 cases the inflated lung showed generalized emphysema alone (eight were from female subjects). In the remaining 75 there was centrilobular, in addition to generalized, emphysema (two were from female subjects). The recognition of the centrilobular disease depends upon the identification of the lobular outline, and for this purpose it is essential to fix the lung in the expanded position. The lobules (Basle terminology, syn. secondary lobules of Miller) are the smallest discrete units of the l ung enclosed by fibrous septa. In this paper they will be called simply lobules. They are polygonal in section and approximately 1 to $2 \mathrm{~cm}$. in each dimension (Fig. 1). Emphysematous spaces tend to collapse in $\mathrm{fresh}$ necropsy material and become distorted and torn when the unfixed lung is cut. When the lung is fixed in expansion, however, and then cut and examined under water the interlobular septa and their relationship to the emphysematous spaces $\mathrm{can}$ usually be identified. The septa show as fine lines and often lobules contrast with each other by their differing degrees of congestion. Even

FIG. 1.-Cut surface of a lung showing interlobular septa and centrilobular emphysema. $\times 2 / 3$. Man aged 52. Cough and dyspnoea eight years. in the normal lung, the septal outlines of lobules vary in clarity, and the lobules may only be comp pletely enclosed in some areas. As a rule the septa are best developed around lobules near the periphery of the lung.

\section{Gross Appearances of Centrilobular EMPHYSEMA AND ITS DISTINCTION FROM GENERALIZED EMPHYSEMA}

Owing to their small size the normal air spacest as seen in large sections of the lungs from young adults can be identified only with difficulty when examined macroscopically. The spaces become larger with age, and in the normal lungs of thछ elderly may be nearly $1 \mathrm{~mm}$. in diameter and easilyo visible. In generalized emphysema the air spaces are uniformly enlarged and to a greater degrees than occurs simply as an age change, so that the become individually identifiable even when the्ष

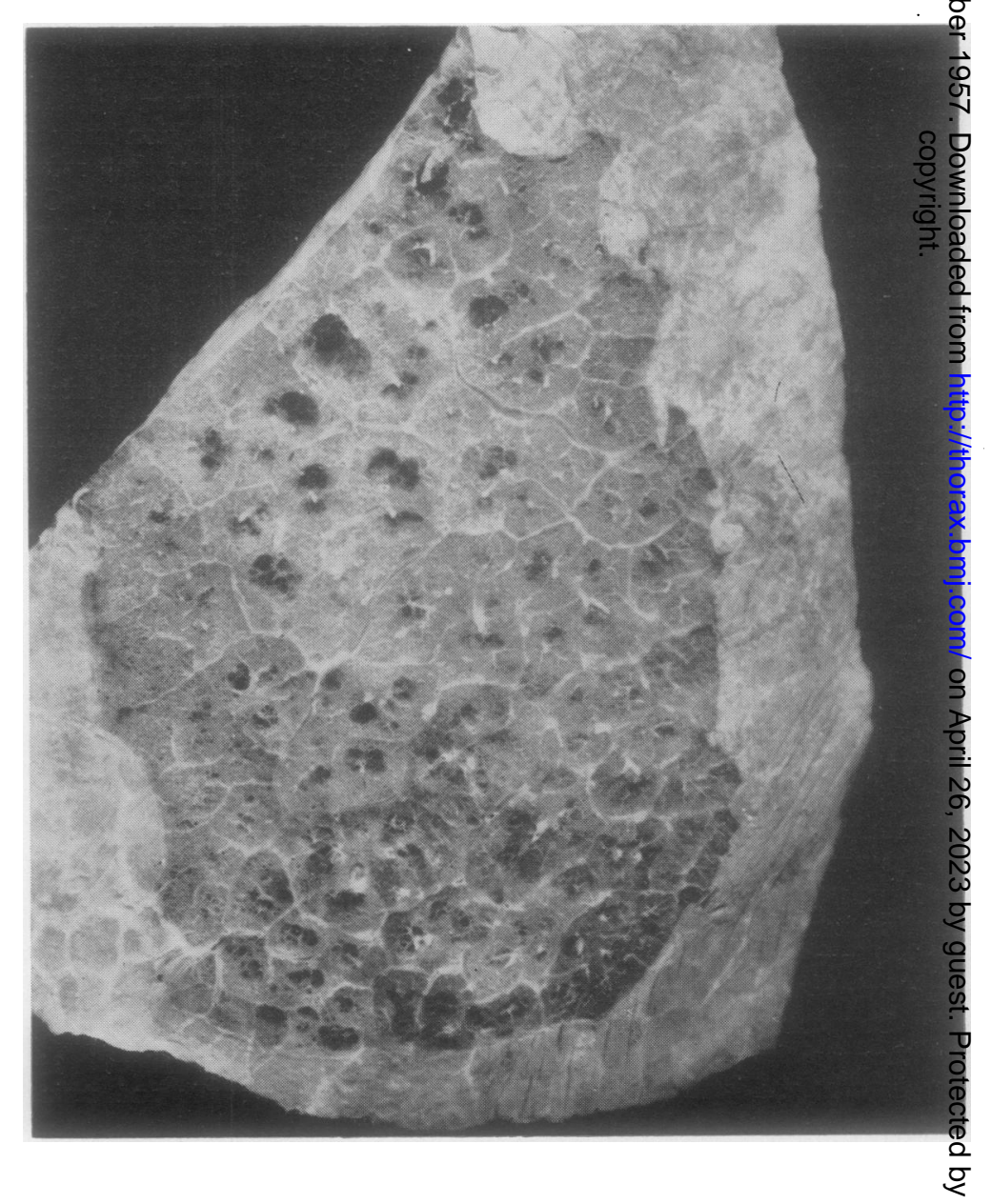




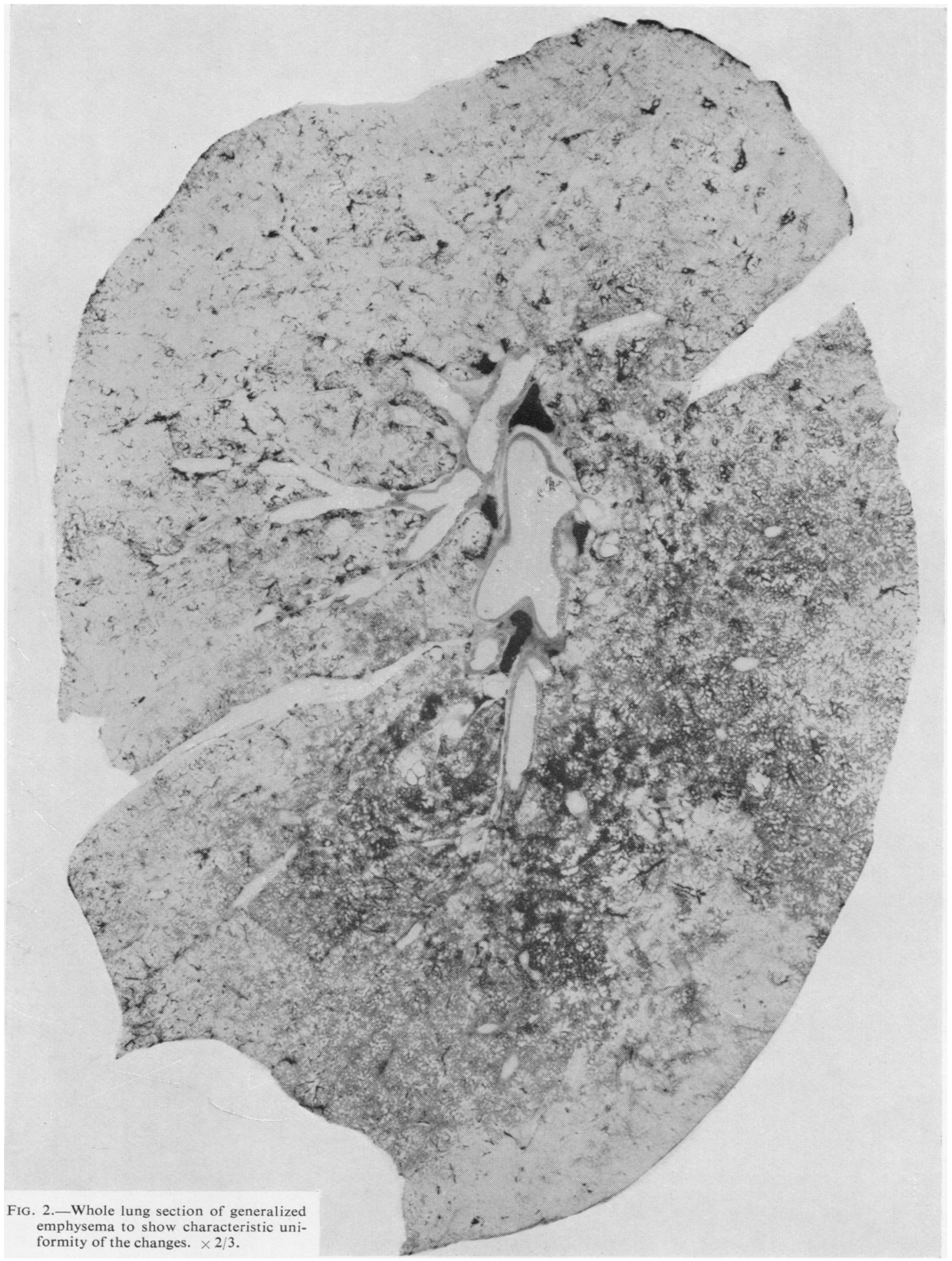

훙 


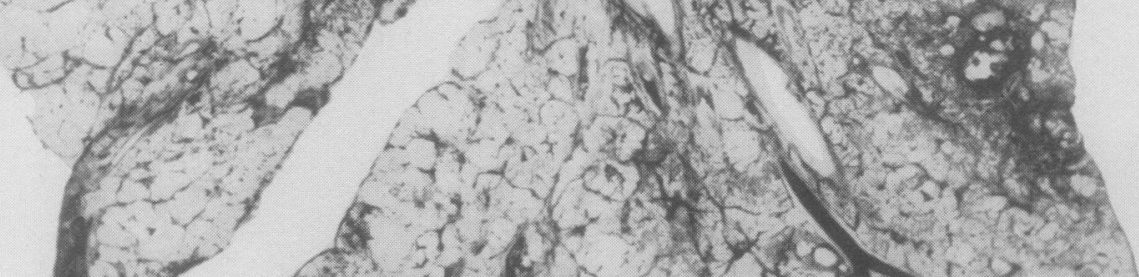

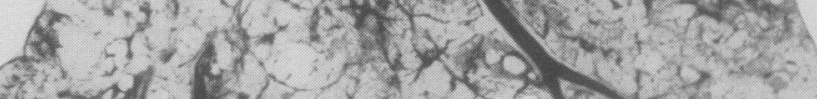

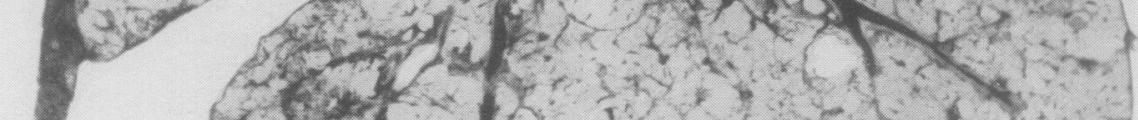

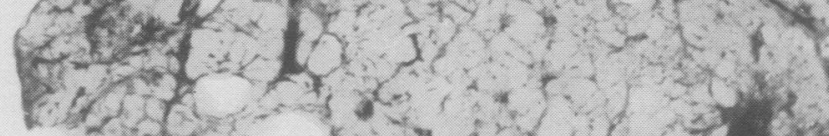

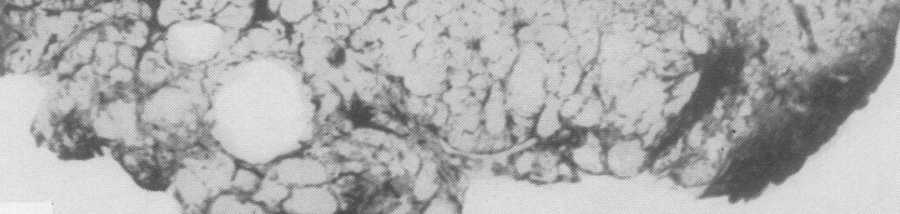


section is held at arm's length. In this condition there is no noticeable difference in the degree of the change from one lobule to another (Fig. 2). In centrilobular emphysema the spaces are larger, but the most obvious features which distinguish this from generalized emphysema are the irregular distribution and the markedly unequal involvement of individual lobules (Figs. 1 and 3). Generalized emphysema tends to be slightly more marked in the upper than in the lower half of the lung, but the distribution of centrilobular emphysema is inconstant and frequently limited to only parts of the lung.

The centrilobular origin of emphysematous spaces is best observed in lobules not severely diseased. The changes appear destructive even in the smallest lesions, and the ragged air spaces at the centre contrast with the normally patterned lung tissue at the periphery of the lobule (Figs. 1 and 4). The more damaged the lobule, the nearer to the interlobular septa do the emphysematous spaces extend, and they may occupy the total volume of a lobule. The bronchioles and the branches of the pulmonary artery supplying the lobule then cross the emphysematous tissue in an arborizing manner.

The emphysematous spaces form at a number of the sites around the centre of a lobule. At each site a cluster of emphysematous spaces develops which is mulberry or dentate in outline (Figs. 1 and 4). The border of a cluster is thin and delicate, while the whole appears subdivided by strands of tissue into a number of loculi. The clusters in any particular secondary lobule are most numerous when small. The clusters become confluent as they enlarge. When small, two, three, or four separate clusters are visible in one plane of section of the lobule. Carbon in amounts common in the lungs of town dwellers is collected around the spaces and in their partitions, thus helping to delineate the lesion. It is difficult to appreciate the centrilobular origins of the disease in parts where the changes are advanced and where there is confluence of the spaces of adjacent lobules. There is especial difficulty in areas where septa are poorly defined. In severely affected lungs it is necessary to examine the areas least severely diseased and where the septa are better formed, in

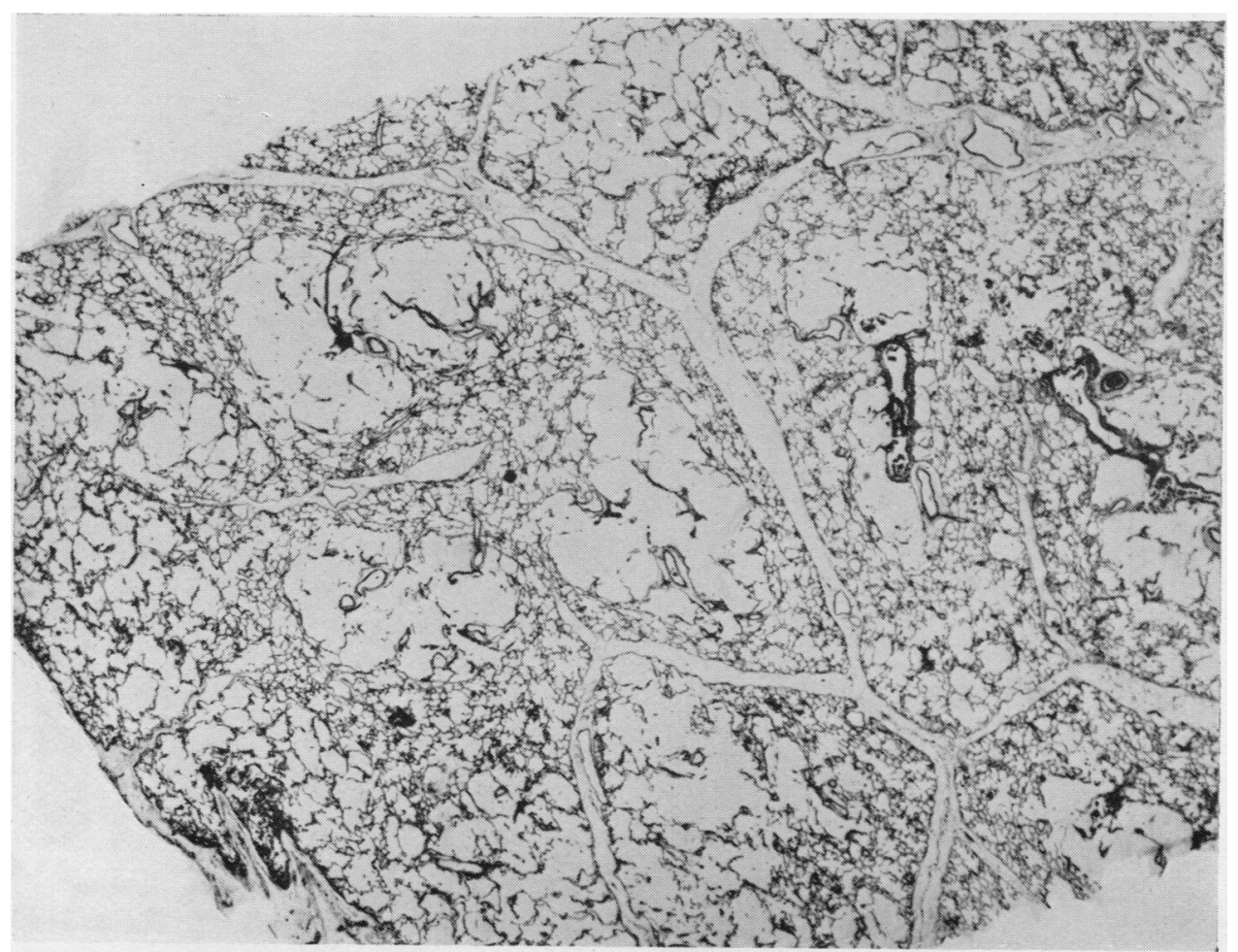

FIG. 4.-Histological secton showing lobules separated by septa and containing central emphysematous spaces. $\times 5$. 
order to identify that the emphysema originates in a centrilobular position.

\section{The Microanatomy of Centrilobular EMPHYSEMA}

The anatomical lobule is to be differentiated from the microscopic unit of the lung structure described by Miller (1947) as the primary lobule. The latter consists of an alveolar duct with its atria and saccules, all with their alveoli.

The respiratory bronchioles also bear alveoli. Heppleston (1953) reviewed and revised the description of the anatomy of the respiratory bronchioles in the adult human lung, and his account will be adopted (Figs. 5 and 6). He found that three successive orders of respiratory bronchioles (R.B.) usually arise from a terminal (nonrespiratory) bronchiole, and from the last order branch the alveolar ducts to form the "primary
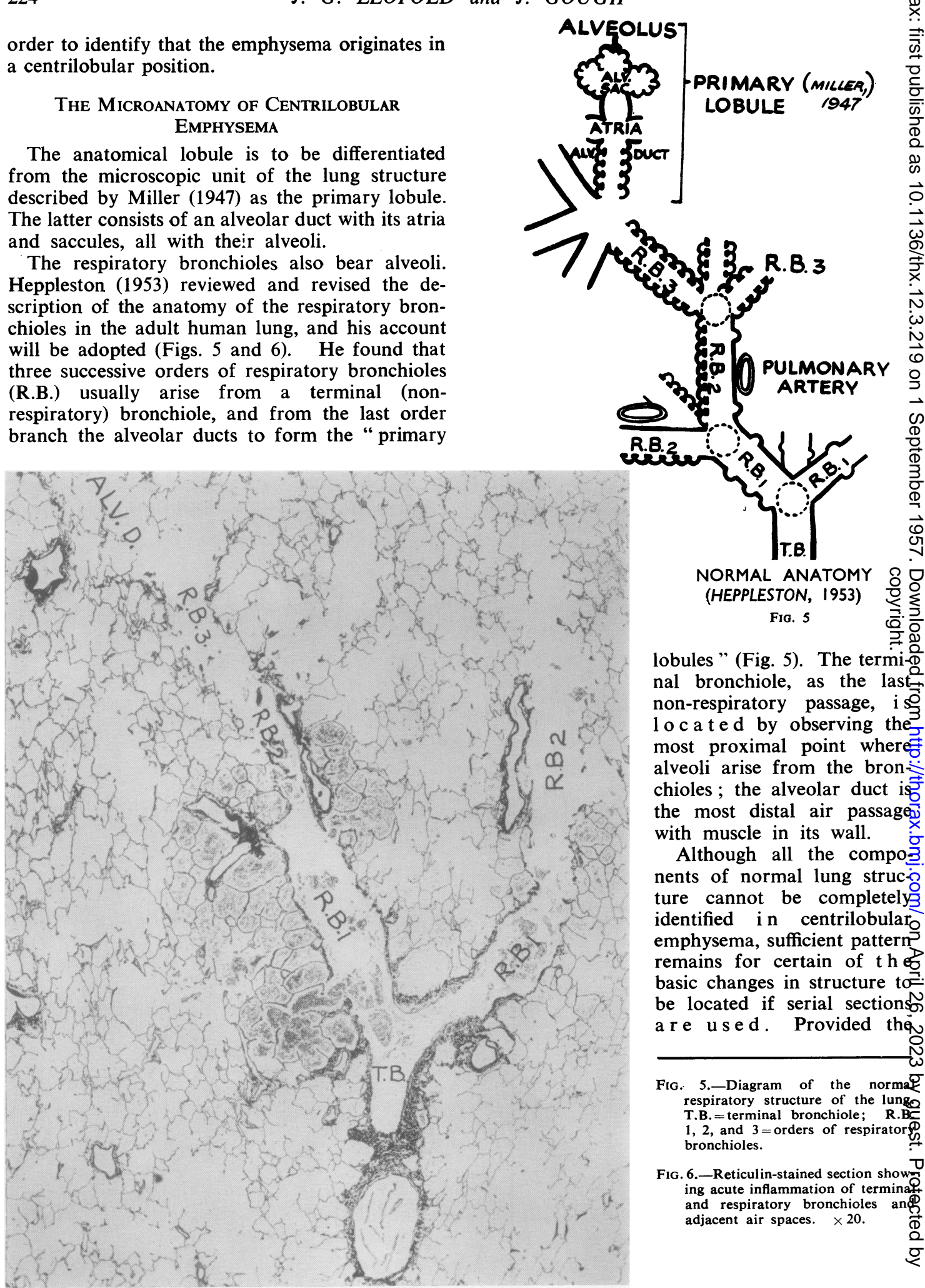

lobules" (Fig. 5). The terminal bronchiole, as the last non-respiratory passage, i so loc a ted by observing the most proximal point where alveoli arise from the bron chioles; the alveolar duct is the most distal air passagen with muscle in its wall.

Although all the compos nents of normal lung struc. ture cannot be completely identified in centrilobularo emphysema, sufficient pattern remains for certain of $t h$ b basic changes in structure to be located if serial sections a re used. Provided the

FIG. 5.-Diagram of the normat respiratory structure of the lungo T.B. = terminal bronchiole; R.BC 1,2 , and $3=$ orders of respirator $\$$ bronchioles.

FIG. 6.-Reticulin-stained section show ing acute inflammation of terminat and respiratory bronchioles an\& adjacent air spaces. $\times 20$. 


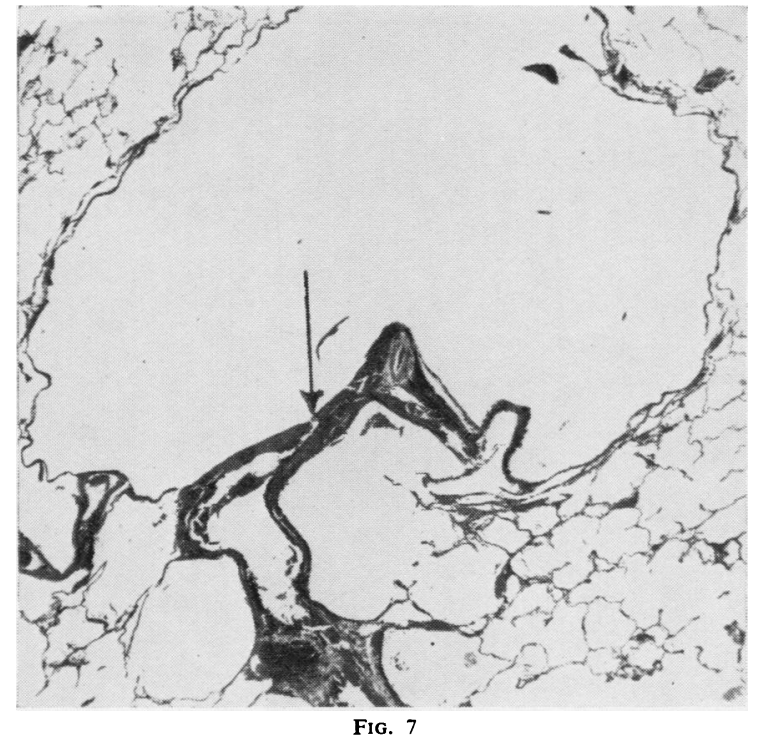

identified, their existence around the spaces is suggested by the occurrence of structures having smooth muscle in their walls. The shape of an emphysematous cluster is inconstant, sometimes being rounded and clearly defined (Fig. 7) and sometimes being dentate in outline and ill-defined (Fig. 8). The boundary to an emphysematous space is always formed by respiratory structures with no trace of fibrous thickening. Each emphysematous cluster is marked off into loculi by partitions, which do not, however, form complete divisions. These partitions radiate from one bronchiole which provides the airway to the cluster (Figs. 8, 9, and 14). This bronchiole will be called the "supplying" bronchiole. It is accompanied by a branch of the pulmonary artery which follows the partitions across the emphysematous spaces, dividing and supplying the surrounding lung. A " supplying" bronchiole, the emphysematous loculi with which it communicates, and the

disease is only moderately advanced, complete "primary lobules" c a n be identified around, i.e., distal to, the emphysematous spaces. The "primary lobules" are usually distorted in shape and difficult to trace fully. When alveolar ducts are traced proximally they open directly into emphysematous spaces and not, as normally, into recognizable respiratory bronchio l e s. Exceptionally, an alveolar duct is joined to a centrilobular space by a short length of the last order of respiratory bronchiole. Even when $\mathrm{the}$ alveolar ducts are so distorted that they cannot be

FIG. 7.-A rounded and sharply defined centrilobular space connected to the "supplying" bronchiole by a valvular and narrow opening. $\times 20$.

FIG. 8.-Triloculate emphysematous cluster arising without anatomical obstruction from a "supplying" bronchiole; partitions between the loculi radiate from its end. $\times 20$.

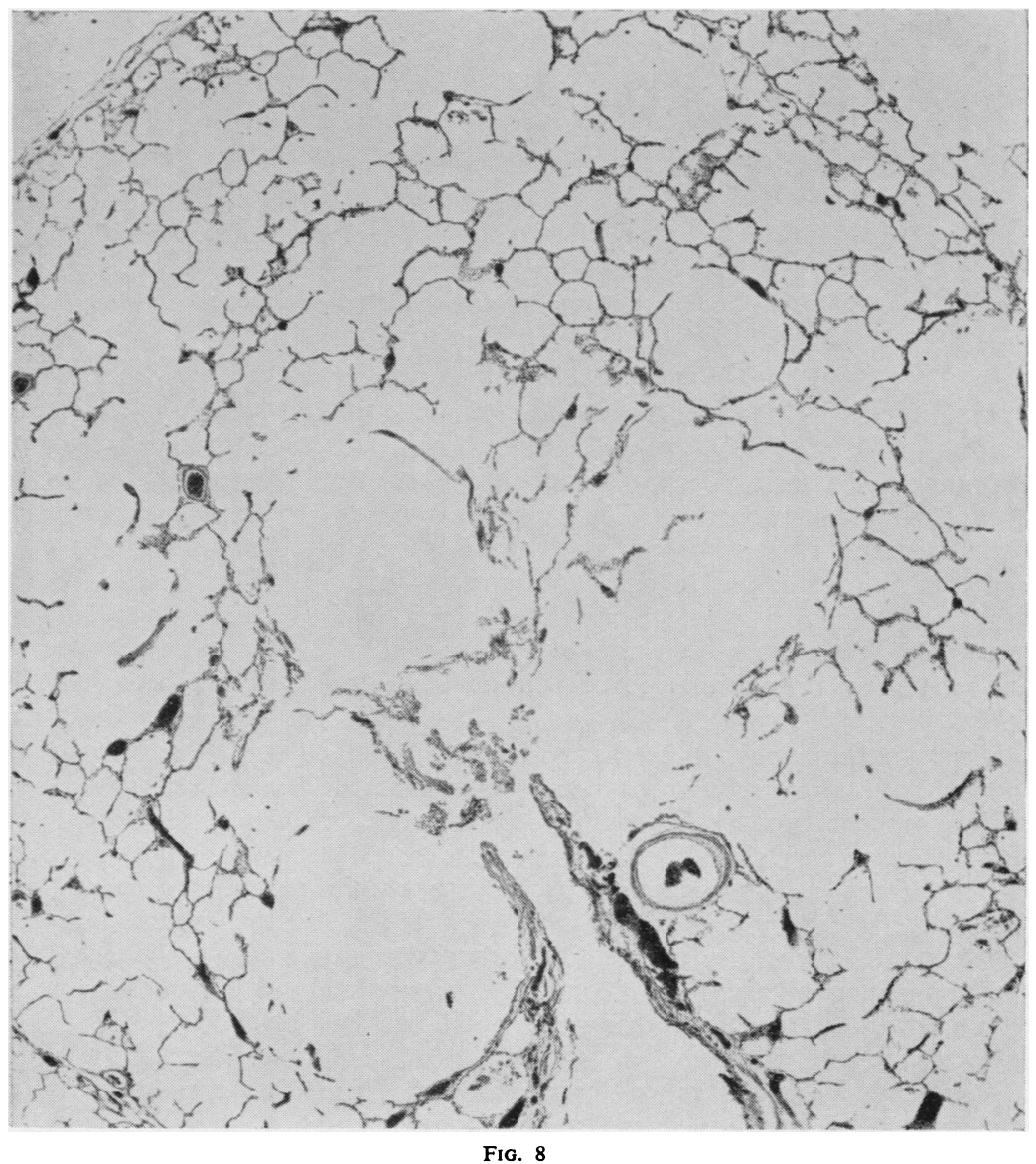

FIG. 8 


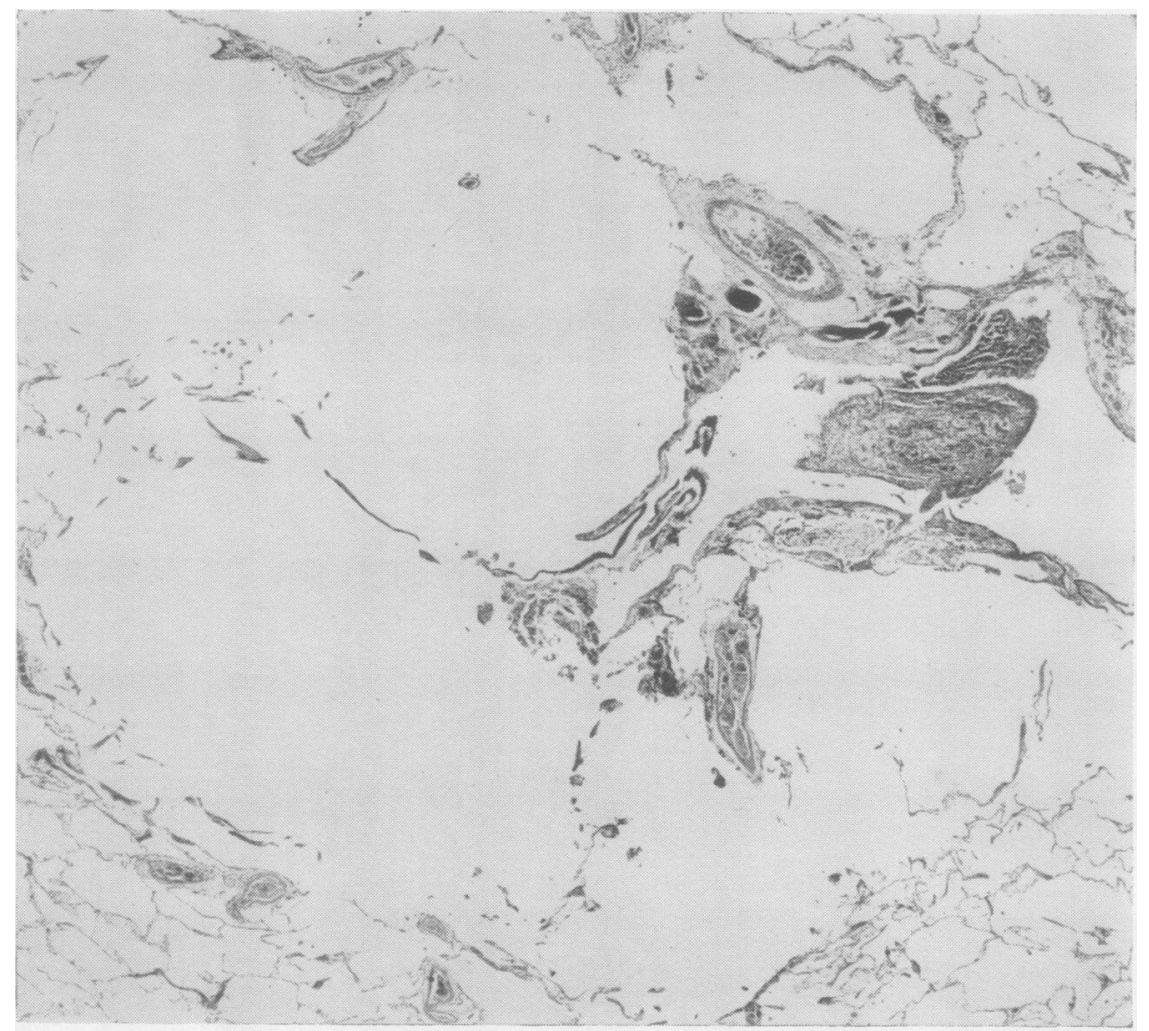

FIG. 9.-The origin of a cluster of spaces from one branch of a bronchiole which is dilated and contains organizing inflammatory exudate in its lumen. $\times 20$.

arrangement of structures in the immediately surrounding tissue, all follow the distribution of the pulmonary arteriole which accompanies the "supplying" bronchiole. This observation suggests that the alveolar ducts, etc., which leave the emphysematous space belong to the same structural system as forms the space. The "supplying" bronchiole represents the trunk of the system, and its particular bronchiolar level will be described later.

Examination in serial sections of entire lobules which have centrilobular cavities shows that the emphysema is not compensatory to collapse or fibrosis occurring elsewhere in the lobule (Fig. 4). Patent communications between the bronchioles and the emphysematous spaces are traceable in all lesions, although the calibre of these passages varies (e.g., compare Figs. 8 and 17). Complete obliteration of the "supplying" bronchioles has not been seen.

Certain general inferences can be drawn from the preceding findings : (a) In the smaller and therefore apparently earlier lesions the centri lobular emphysema does not primarily involv $\vec{E}$ saccules, atria, or alveolar ducts. Undoubtedly al\$ these parts may become incorporated in the space as the emphysema extends within the lobules (b) When traced proximally alveolar ducts leadi directly into emphysematous spaces. Thus respira응 tory bronchioles are components of the latter although their individual identity has become ob scured in their expansion. Bundles of smoot muscle occur in the partitions of emphysematous: clusters, which is consistent with the view that th spaces originate from respiratory bronchiolesin How many orders of respiratory bronchioles ar\& included cannot be decided from examination of the spaces, but this may be deduced if the brone chiolar level of the "supplying" passages can be determined. Special attention has been directed t? this.

The "supplying" bronchioles show histologicat" changes of chronic inflammation and may appea to be non-respiratory, i.e., they do not bear alveoli? 


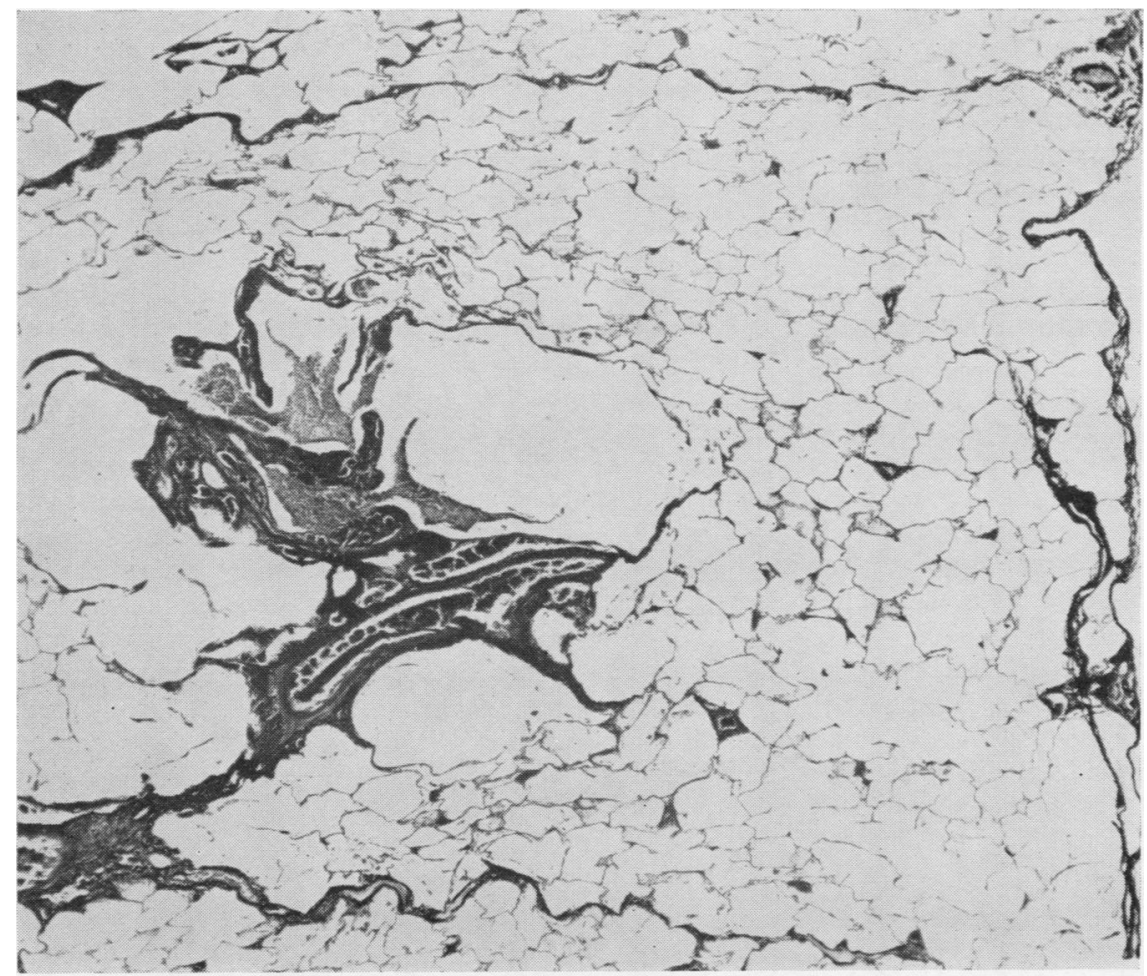

FIG. 10.-A small cluster of emphysematous spaces arising from a bronchiole, thick walled with inflammatory exudate, which is cut nearly end on. This " supplying" passage to the spaces is a branch of the bronchiole shown cut longitudinally in Fig. $12 . \times 20$.

but, should respiratory bronchioles be affected by inflammation, the alveoli which are their distinguishing features can become obliterated. Accordingly, the " supplying" bronchioles of centrilobular emphysema have been carefully examined for traces of alveoli. Normal alveoli have not been found, but three varieties of change, each of which suggests the previous existence of alveoli, are of frequent occurrence. These are intramural cystic spaces, apertures in the wall (Fig. 14), and diverticula which extend from the lumen to beyond the wall of the bronchiole. Unlike the normal alveolus, however, these structures are lined by cubical or columnar cells. The diverticula and the apertures are thought to indicate sites where alveoli arose from the bronchioles, although the apertures may be Lambert's (1955) accessory bronchiole-alveolar communications which she finds even in the normal lung. The small cystic spaces are probably alveoli which have become enclosed by the organization of exudate around the "supplying" bronchiole. These alveoli may have arisen from that bronchiole or belong to other structures which are adjacent.

On the evidence of the above findings we suspect that the "supplying" bronchioles are of respira-

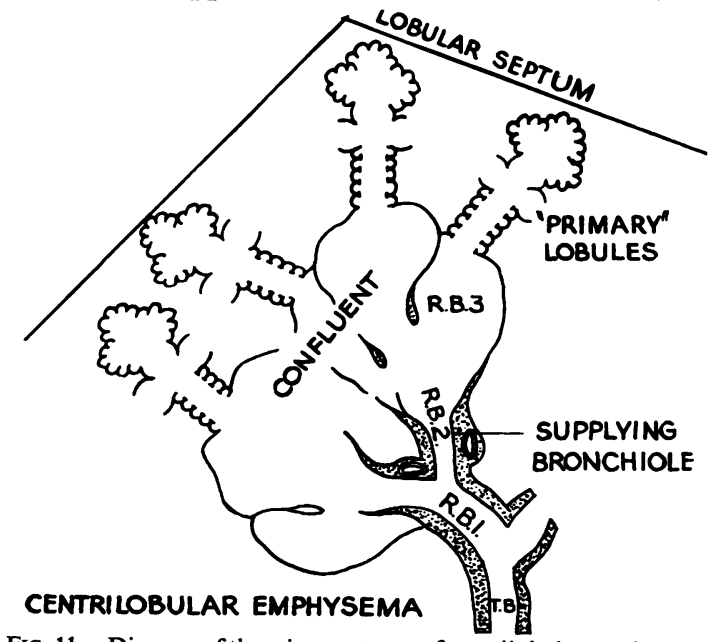

FIG. 11.-Diagram of the microanatomy of centrilobular emphysema. 
tory type. Occasionally the bronchiole proximal to the "supplying" passages is also regarded as being respiratory. Sometimes conclusive proof of the respiratory origin of the "supplying" bronchiole is obtained, usually on indirect evidence. A bronchiole may be observed with its branches unaffected or so slightly affected by emphysema as to allow one to trace back and determine that it was respiratory (Fig. 12). Such a bronchiole may be of the same bronchiolar generation as less easily identified passages which are the "supplying" bronchioles to the emphysematous clusters (Fig. 10). Direct proof has been seen on only one occasion. Here, normal alveoli are present in a bronchiole which later divides to give the " supplying " passages of emphysematous clusters (Figs. 13, 14). Even in this example the "supplying" passages have lost their alveoli which are replaced by apertures.

Even when it is difficult to decide the origin of the "supplying" passages from the serial sections, certain features may still assist their recognition as respiratory bronchioles. Typical features are the

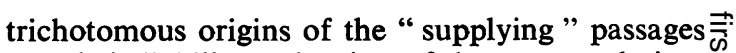
and their liability to be sites of dust accumulation $\frac{?}{6}$ The relationship of "supplying" bronchioles to등 branches of the pulmonary artery is reminiscent of $\frac{\bar{D}}{\bar{D}}$ respiratory bronchioles of the second order. Ad- $\widetilde{\Phi}$ jacent to the artery the wall of the "supplying "응 passage is always complete, whereas walls awayon from the artery have apertures (Fig. 14), thus $\vec{\circ}$ differing from the normal structure only by pos- $-\overrightarrow{-}$ sessing apertures in the position where normally $\vec{\omega}$ there are alveoli. Direct comparison of the size of the lesion of emphysema with the respiratoryx structure of the normal lung and the position of $\vec{N}$ the spaces in relation to the margins of the lobule $\omega$ are features which can be of great assistance when ${ }_{\overrightarrow{0}}$ on other grounds the anatomical level is obscure.

Since it is more or less certain that the " supply-? ing "passages in centrilobular emphysema are $\vec{c}$ modified proximal respiratory bronchioles, onlyథ those of the more distal orders can have formed $\underset{\mathbb{D}}{+}$ the spaces. The emphysematous loculi represent 3 passages which had lain contiguous with one⿻上丨 another, the tissue intervening between them $\vec{A}$

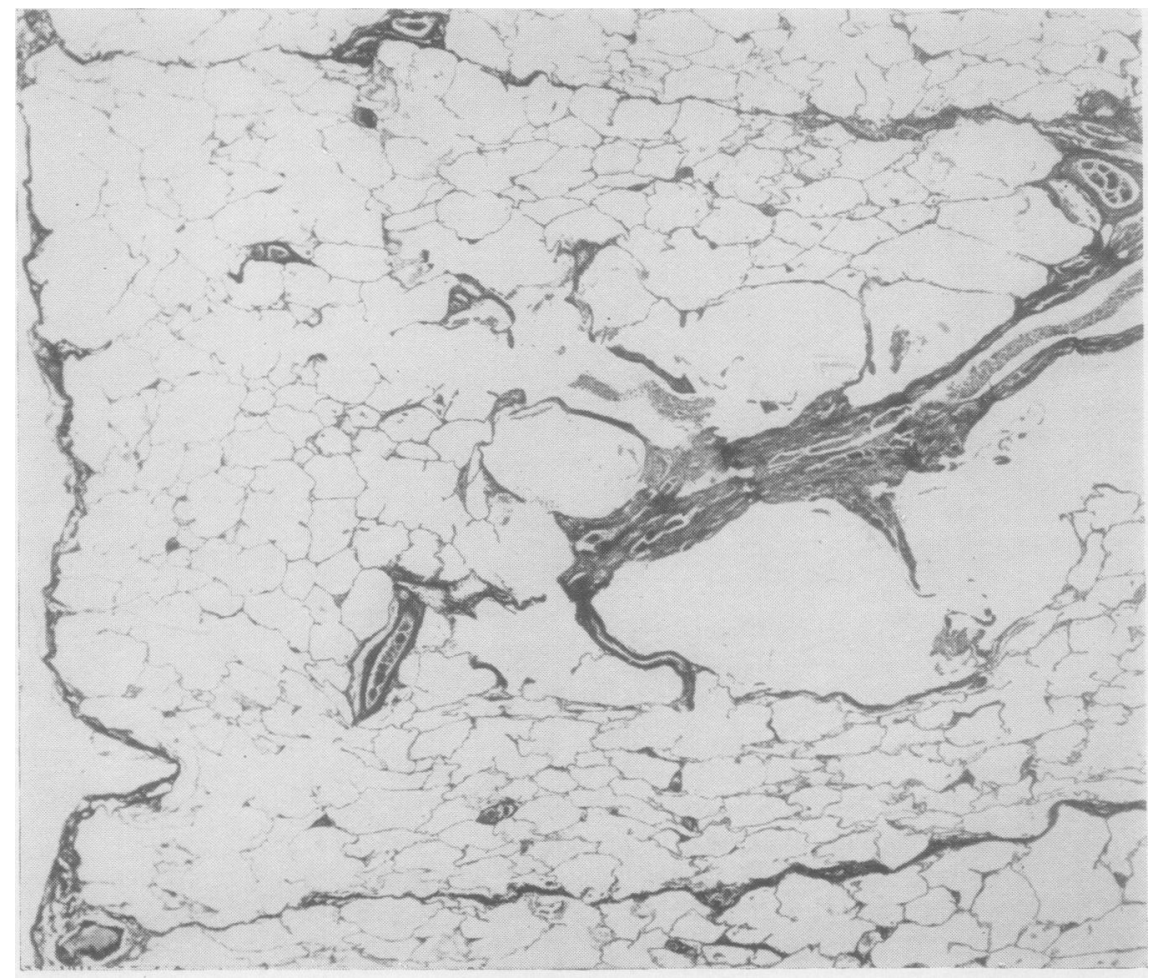

FIG. 12. - From the distal end of a narrowed bronchiole, passing to the left, is a short passage which leads to respiratory bronchioles of the last order. Thus, a bronchiole which is narrowed on dividing leads to emphysematous (Fig. 10) and non-emphysematous tissue. $\quad \times 20$. 


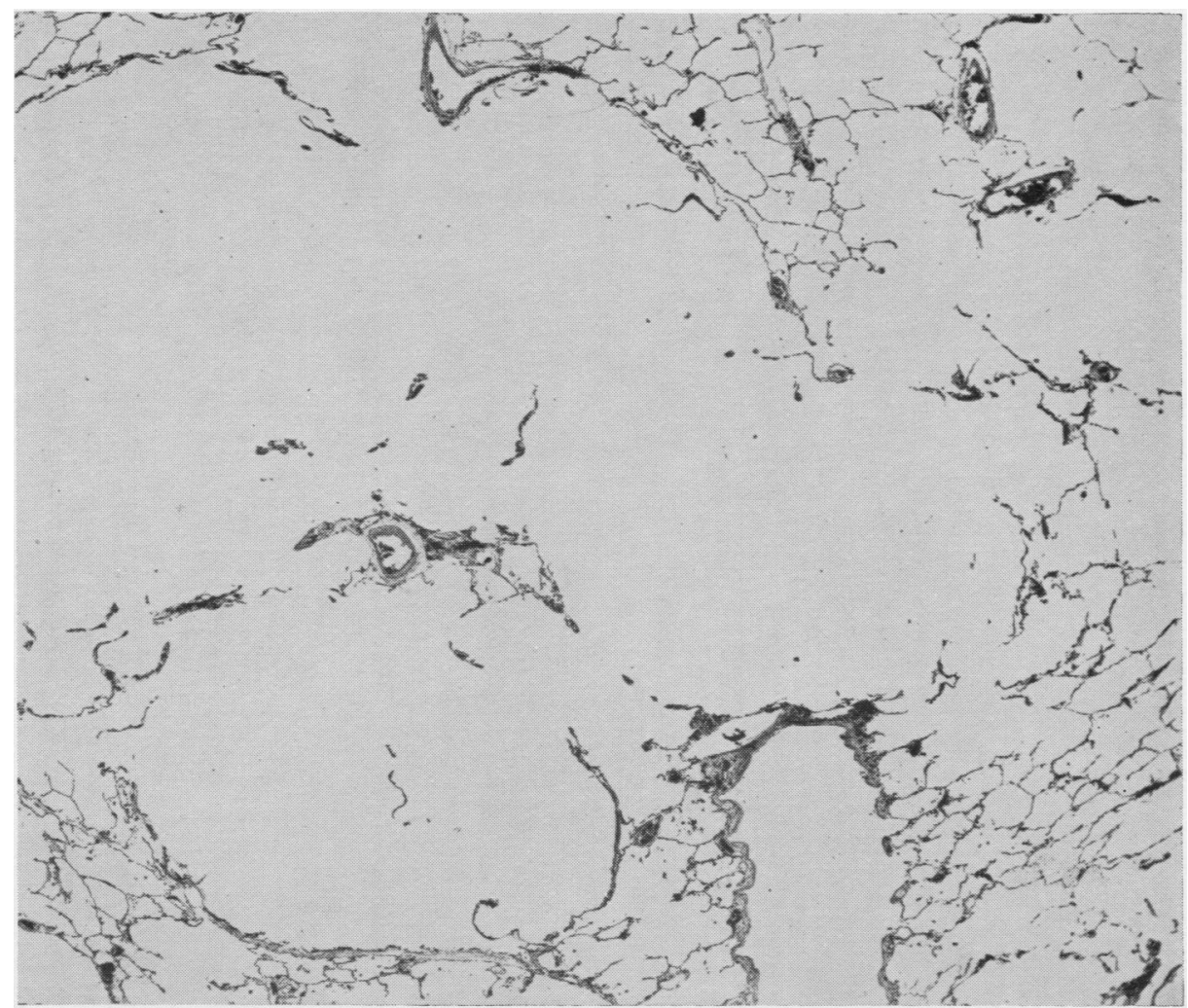

Fig. 13.-Alveoli pouch from the wall of a bronchiole (lower right) which later divides into the "supplying" bronchioles of the emphysematous space. $\times 20$.

having been partially destroyed. The result is a confluent space retaining remnants only of the walls of its constituent structures (Fig. 11). Recurrent air passages will also become included in the spaces. In some instances the respiratory bronchioles of the last order appear mainly to form the emphysematous spaces, but the expanded distal part of the second respiratory bronchiole is usually included, its proximal part forming the "supplying" passage. The cluster of emphysematous spaces arising from any one "supplying" bronchiole rarely exceeds $3-4 \mathrm{~mm}$. in diameter before fusing with adjacent lesions. The combined space may be nearly a centimetre in diameter. Such large lesions duplicate the general appearance of the smaller lesions of which they are composed, differing only in their size, the number of their loculi, and their connexion with more than one bronchiole.

\section{Chronic Inflammatory Changes in} CENTRILOBUlar EMPHYSEMa

We present evidence to support our main findings that, when chronic inflammation is limited to bronchi, any accompanying emphysema is of the general type, but when inflammation also extends to the smallest bronchioles centrilobular emphysema is one of the results. Such peripheral extension of inflammation may occur very irregularly in the lung, so that unaffected lobules are contiguous with lobules showing centrilobular emphysema, giving to this type of emphysema its characteristic uneven distribution.

In all 75 cases with centrilobular emphysema histological examination reveals widespread changes of chronic bronchitis. In many there is also acute bronchitis. The chronic changes involve main, lobar, and segmental bronchi, while in the parts of the lung where centrilobular emphysema is present there is extension of inflammation to the bronchioles. Laennec (1819) and Rokitansky (1852) appreciated that chronic bronchiolitis frequently causes the dilatation of bronchioles. A good demonstration of this dilatation is given by the large lung sections. Nearly all with centrilobular emphysema show dilated bronchioles close to the pleural surface. 


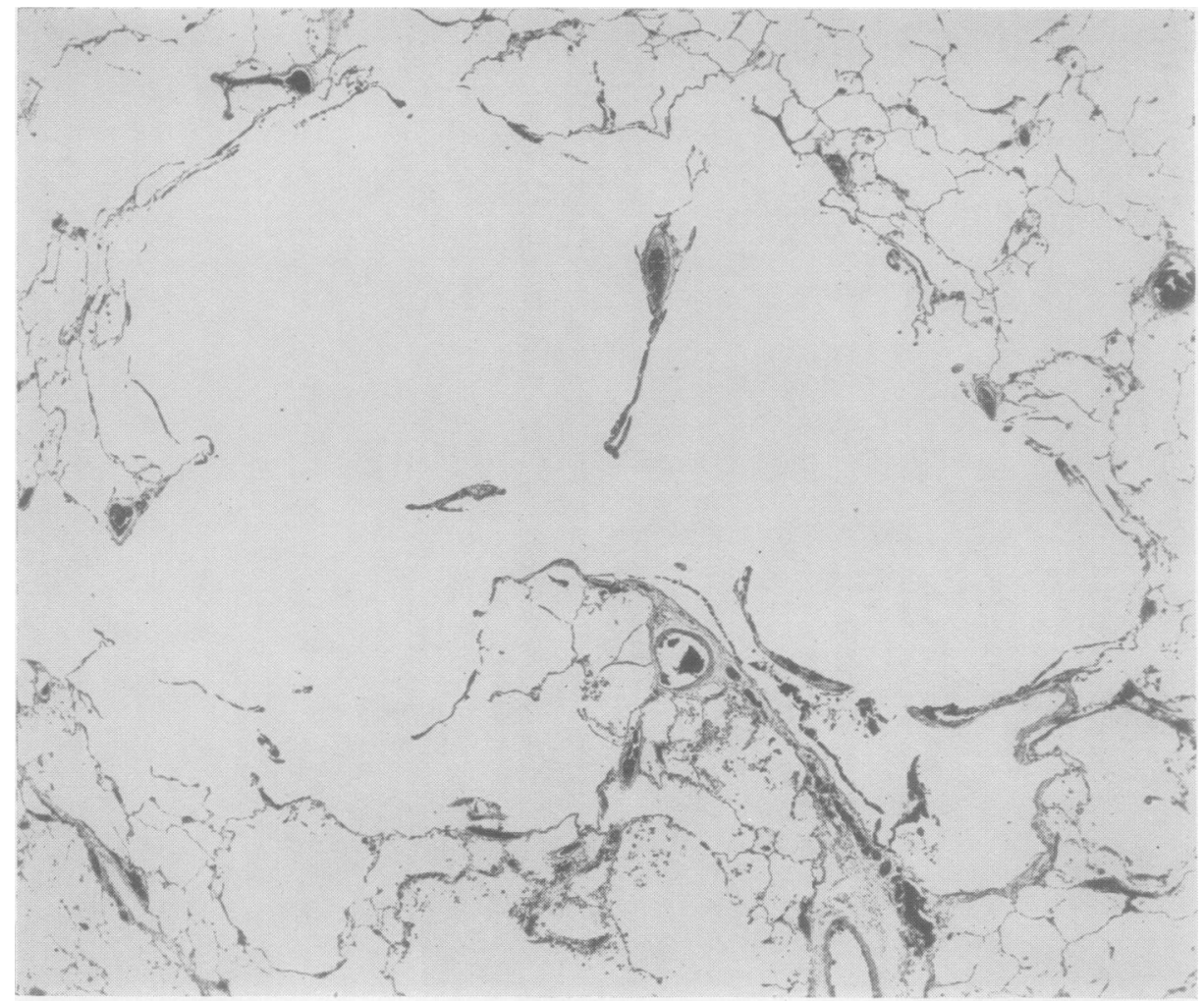

FIG. 14.-One of the "supplying" passages (same lesion as Fig. 13), with an aperture and slight thickening of the wall opposite the pulmonary artery. $\times 20$.

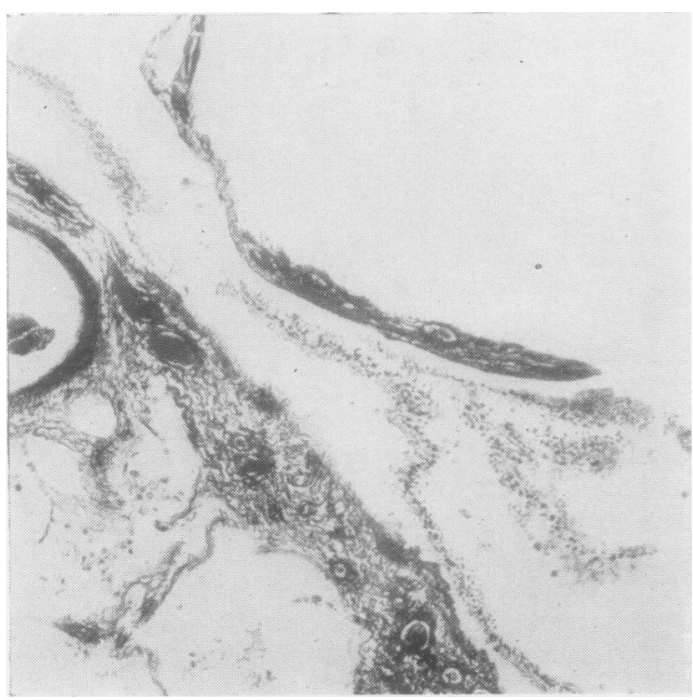

FIG. 15. - Thickening of the "supplying" bronchiole in Fig. 14 reticulin stain). $\times 60$.

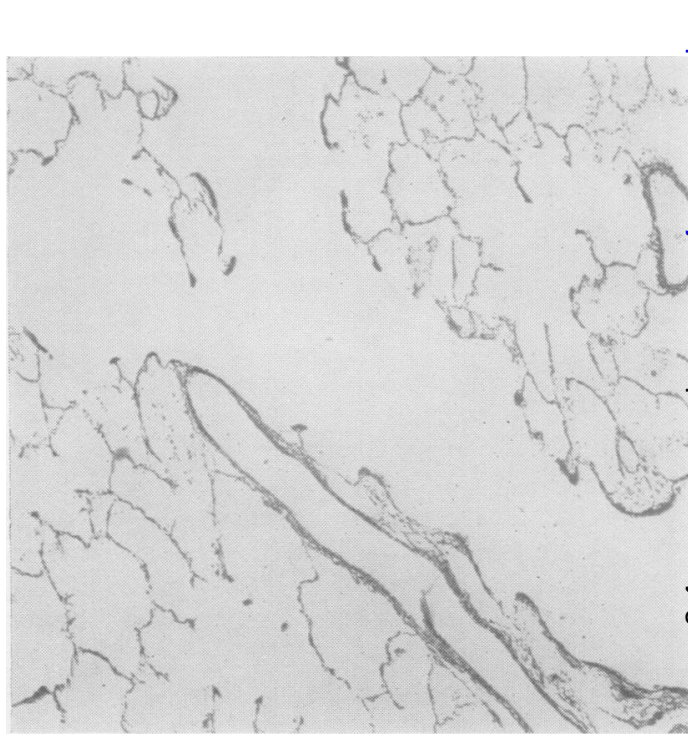

FIG. 16.-For comparison, a normal R.B.2. (reticulin stain). $\times 60$. 
The changes of chronic inflammation in the bronchi and bronchioles consist of lymphocyte and plasma-cell infiltrations and occasionally metaplasia of the lining epithelium to a stratified type. More commonly this epithelium is represented only by occasional basal cells, arranged irregularly, along a thickened basement membrane. Increased density of reticulin and, less commonly, diminution in numbers of elastic fibres, occur. At non-respiratory levels complete collagenization of the bronchial or bronchiolar wall is uncommonly seen, but such severe fibrosis is more frequent in the "supplying," i.e., respiratory, bronchioles to the emphysematous spaces.

Inflammation InVolving "SupPlying" BronChiole and Emphysematous Cluster. - In lobules showing centrilobular emphysema the bronchiole inflammatory changes have extended into the centres of the lobules, although sometimes the evidence of inflammation consists only of fibrosis or other non-specific changes. Chronic inflammatory cell infiltration is present in 78 of the bronchioles identified as "supplying" the 90 lesions of emphysema examined in serial sections. Often infiltration is more intense here than at the level of the lobar bronchi or non-respiratory bronchioles of the same lung. Loss of elastic and muscle fibres and their replacement by fibrous tissue are frequent findings. Similar changes extend into the partitions between the loculi of the emphysematous cluster, in particular into those parts which are nearest the "supplying" passage. There are no inflammatory changes of any sort at the periphery of the emphysematous spaces. The epithelium lining the "supplying" bronchioles is columnar or cubical and occasionally contains goblet cells. Normal proximal respiratory bronchioles have neither a columnar lining nor goblet cells. This modification of the lining probably represents a response to inflammation. Where increase of connective tissue is the main evidence of inflammation, appreciation of its significance may depend upon recognizing the anatomical level of the "supplying" bronchiole. Unless comparison is made with the corresponding normal structure, changes of a minor degree could easily escape notice (compare Figs. 15 and 16). This comparison could not always be made, although the fact that in no instance are normal alveoli identifiable in the "supplying" passages, structures which we think were originally respiratory bronchioles, goes some way to support the view that inflammation has occurred in all lesions.

It appears that inflammatory exudate may become organized around and within the lumina of
“ supplying" bronchioles (Fig. 9), although where damage to the wall is severe this cannot be decided because no trace of the wall may remain. Organization of intrabronchiolar exudate is unusual and has been described as a distinct entity in bronchiolitis fibrosa obliterans. In this condition respiratory rather than non-respiratory bronchioles show the organization (McAdams, 1955). Eleven of the 90 lesions of centrilobular emphysema examined by serial methods have intrabronchiolar organization in the "supplying" branches. The amount of connective tissue in the walls of some "supplying" bronchioles is more than can be accounted for by bronchiolitis alone, having been increased by the organization of peribronchiolar pneumonic exudate. Indeed, it is doubtful whether a bronchiolitis will affect respiratory bronchioles without pneumonic consolidation occurring in the surrounding alveoli (Fig. 6). Bronchiolitis with a peribronchiolar pneumonia of the distribution concerned in centrilobular emphysema has been a feature of particular comment in respiratory infections from influenza (Opie, Blake, Small, and Rivers, 1921 , p. 166) and in lesions produced by war gas poisoning (Winternitz, 1920, Figs. 14 and 17, and p. 58). Both these conditions can be important in the early history of chronic bronchitis in persons who, at necropsy, may be found to have centrilobular emphysema.

Pulmonary Vessels.-Right ventricular hypertrophy (defined as a thickness of $6 \mathrm{~mm}$. or more) was present in 41 of the cases with centrilobular emphysema, but in only nine cases with generalized emphysema alone. Sclerotic changes occur in all sizes of pulmonary vessels in emphysema. We have measured the degree of thickening of pulmonary arterioles in hypertrophic emphysema, grouping our cases into those with and without right ventricular hypertrophy. The differences were not statistically significant, although we were left with the impression that there was a greater degree of arteriolar thickening in lungs with right ventricular hypertrophy. Whether the pulmonary arteriolar changes are the result of bronchiolitis or are secondary to pulmonary hypertension is uncertain.

\section{Chronic Bronchitis in Lungs With Generalized bUt No CENTRILObular EMPHYSEMA}

The 65 cases with a pure generalized emphysema have been examined histologically for evidence of chronic inflammation in the bronchial tree. The histology of the bronchi and bronchioles appeared normal in eight cases, and in a further four the only abnormality is metaplasia of the lining epi- 
thelium of the main bronchi. In 36 cases chronic inflammation involves the main, lobar, and medium-sized bronchi. In 17 these changes are confined to the main bronchi and lobar branches. Chronic inflammation affecting bronchioles is infrequent. We emphasize as the main finding that there is no recognizable involvement of the respiratory bronchioles, and these cases therefore contrast markedly with those having centrilobular emphysema.

Heppleston (1953), in his investigation of the microanatomy of chronic generalized vesicular emphysema, found that the respiratory bronchioles were normal, apart from slight and inconstant dilatation of the last order. The enlarged air spaces in this condition were dilated alveolar ducts and more distal parts of the primary lobule. The dilatation did not result in destruction of tissue, unless it was severe, and until this occurred the anatomical pattern was recognizable, although expanded.

\section{Discussion}

Pathogenesis of Centrilobular Emphysema. -This is discussed in relation to $(a)$ inflammation, (b) the calibre of bronchi and bronchioles, and (c) weakness of emphysematous spaces.

(a) Inflammation.-Chronic bronchitis and bronchiolitis are invariable findings in lungs with centrilobular emphysema. Coughing, which may induce abnormal changes in the general intrathoracic pressure, is hardly likely to produce these irregularly distributed lobular lesions. The primary cause must be located in the lobules. Chronic bronchial inflammation is not confined to emphysema of this pattern and commonly accompanies generalized emphysema, but extension of the inflammation to bronchioles is infrequent in the latter, and respiratory bronchiole involvement is peculiar to centrilobular emphysema The difference strongly suggests that the centrilobular emphysema is due to the inflammatory changes in the respiratory bronchioles. A bronchiolitis involving respiratory bronchioles, with pneumonia limited to the alveoli which arise from and are adjacent to these bronchioles, would appear to be the basis of centrilobular emphysema (Fig. 6). Engel (1947) called peribronchial pneumonia of this distribution peduncular pneumonia. $\mathrm{He}$ wished to emphasize that it was a pneumonia at the pedicle of the respiratory structure, a crucial site in the defensive responses of lung and bronchi to infection.

In established lesions of centrilobular emphysema the acute changes of inflammation have usually disappeared. However, exudate has be- $\stackrel{\overrightarrow{\vec{D}}}{\overrightarrow{0}}$ come organized, and when specialized tissue, such $\bar{C}$ as muscle, has been lost it is not replaced. From such traces and any cellular infiltration that per- $\frac{\bar{s}}{\partial}$ sists, the nature and limits of the acute inflam- $\stackrel{\mathbb{\Phi}}{\circ}$ matory process can be inferred. The "supplying "N bronchioles and the partitions between the locu' $i$, of emphysematous clusters are sites involved by inflammation. No similar changes are found at $\vec{\omega}$ the periphery of the emphysematous clusters, and $\stackrel{\omega}{\top}$ these structures are not uniloculate cavities, which $\vec{x}$ excludes abscess formation with discharge of the $\overrightarrow{\vec{v}}$ contents into the bronchi, as the manner in which the spaces are likely to have formed. Inflam-iv matory changes become less marked as the parti- $\vec{\omega}$ tions are followed outwards from the "supplying "을 bronchioles and cease when the boundaries of the spaces are reached. The respiratory bronchioles $c s$ which become expanded to form the cluster are $\mathbb{D}$ therefore those at the distal limit of the inflamma- $\overrightarrow{\mathbb{D}}$ tion. Even in the smallest lesions studied the structures which form the spaces have become $\stackrel{\mathbb{D}}{-}$ confluent ; thus we suggest that the emphysematous $\vec{e}$ process begins with tissue damage, expansion $y$ occurring subsequently. As we will show, mechanical stresses alone may not be capable of disrupting healthy lung tissue, the fragmentation of tissue which is typical of centrilobular emph sema depending on weakening by inflammation. $\frac{\bar{Q}}{\circ}$ It is possible that inflammation acts alone to cause $\varrho$ tissue destruction, but the most severe inflam- $\overrightarrow{\vec{O}}$ matory changes are immediately proximal to the 3 spaces where the bronchioles are considerably? thickened by the incorporation of peribronchiolar. exudate. There is little doubt that inflammation is important even though it is difficult to define the mechanism which causes the disruption and expansion of the tissues. Physiological methods applied $\frac{\sigma}{3}$ to clinical cases of emphysema have shown that there is an increased resistance to air flow along윽 the air passages of lungs with this disease (Dayman, 1951 ; Fry, Ebert, Stead, and Brown, 1954 ;웅 McIlroy and Christie, 1954). This finding could be taken to support the view that expiratory obstruction, probably caused by bronchitis, is the N basis of hypertrophic emphysema. In centri-lobular emphysema bronchitis certainly exists and involves the very bronchioles which connect withw the emphysematous spaces. It is necessary, therefore, to examine the pathological evidenceo for or against bronchial obstruction as the cause $\bar{\varnothing}$ of this type of emphysema.

(b) Calibre of Bronchi and Bronchioles.-When $n_{-}^{-}$ the bronchi and bronchioles are followed by the naked eye and with the low-power dissecting $\frac{\text { के }}{0}$ 
microscope, dilatation, and not narrowing, is the usual alteration seen in lungs with centrilobular emphysema. The dilatation can be traced, in this manner, to the bronchioles of the lobules, except for those "supplying" the spaces of emphysema, which are too small to be seen except by microscopy.

The "supplying" bronchioles were therefore examined in serial histological sections and their calibre compared with that of normal terminal bronchioles which are the narrowest passages in the normal lung. Some reduction occurs in 54 $(60 \%)$ of the 90 centrilobular lesions examined, with narrowing to two-thirds of normal, or less, in 11 of these (12\% of the total lesions). But in $40 \%$ the airway along the "supplying" passage is at least as wide as the normal, with some examples of emphysema where the passage is dilated. When narrowing exists it may involve the whole length of the "supplying" bronchiole or it may be limited to the distal extremity (Fig. 17). In examples of the latter type the communications between the "supplying" bronchiole and the emphysema may occur by two or three fine diverging channels. The origin of such channels is from a fork densely enclosed by inflammatory fibrosis and the channels sometimes enter the emphysematous spaces at a tangent. Spherical rather than irregular shapes to the spaces and apparent compression of the surrounding lung tissue are features which suggest that this oblique type of opening acts in a valvular manner (Fig. 7).

In centrilobular emphysema, anatomical narrowing of the airways, when present, affected the " supplying" bronchioles. Narrowing of a severe degree was uncommon, and in nearly half the lesions complete anatomical freedom for airflow appeared to exist. Thus our findings in the centrilobular form of emphysema only partly accord with those of Spain and Kaufman (1953), who reported that the passages corresponding to our "supplying" bronchioles (called by them terminal bronchioles) were narrow and fibrous in hypertrophic emphysema. The size of emphysematous spaces in the centrilobular disease cannot be accurately related to the occurrence and degree of narrowing in the "supplying" passages. Large size partly depends upon previously separate spaces becoming confluent, but emphysematous spaces with severe narrowing to their airway did not usually join with others; they were small and remained well separated from adjoining clusters (compare Figs. 8 and 9 with 17). Narrowing of a bronchiole proximal to a "supplying " passage was exceptional. When it occurred, such narrowing

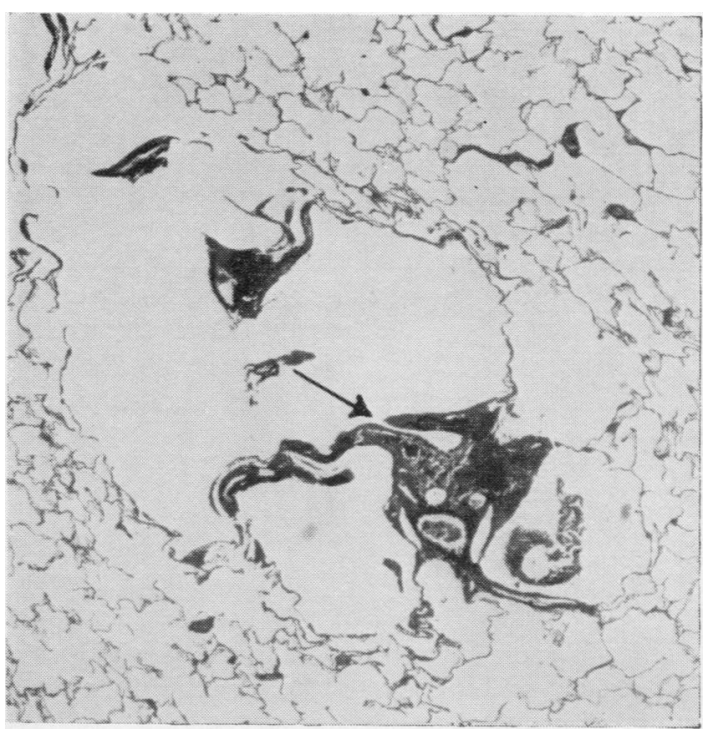

FIG. 17.-One of three short and narrow connexions between a bronchiole and an emphysematous cluster. Inflammatory thickening is marked. $\times 20$.

did not necessarily result in emphysematous clusters developing on all branches (Figs. 10 and 12). Thus centrilobular emphysema is not invariably associated with narrowing. If bronchiolar narrowing leads to emphysema by the trapping of air, dilatation would be expected to involve all the distally placed structures, but the alveolar ducts and sacs are not primarily affected. All these points suggest that bronchiolar narrowing per se is not the cause of the emphysema. This conclusion does not exclude the possibility that narrowing may have been present in the acute stage of the bronchiolitis and later subsided, and does not imply that narrowing may not influence the progress of the lesion once it develops. Although there may be no anatomical narrowing of the airways to the emphysematous spaces, it is possible to suggest two ways in which a check to gas flow may develop in the expiratory phase of respiration. First, gas leaving a large and irregular emphysematous space to flow linearly along the bronchioles may be subject to "eddy effects" at the exit. Secondly, although the "supplying" bronchiole may be of normal calibre, it passes unsupported into the emphysematous tissue and may easily get kinked or compressed.

(c) Relative Weakness of an Emphysematous Space.-Since bronchial obstruction is apparently not the explanation for the emphysema, we put forward an alternative view. If spaces become enlarged from any cause, their walls are propor- 
tionately weakened. The walls of a pressure chamber of large size need to be much thicker than those of a small chamber in order to withstand the same pressure. The rise of internal pressure needed to produce a given degree of expansion in a spherical chamber is inversely related to its radius, and, of all possible shapes of chamber, a sphere is strongest. Green and Shield (1950) give the following formula as governing expansions of large degree occurring from rise of internal pressure within a spherical chamber constructed of a material with rubber-like properties.

$$
\begin{aligned}
\mathbf{P} & =\frac{4 \mathrm{Ct}}{\mathrm{r}}\left(\frac{1}{\lambda}-\frac{1}{\lambda^{7}}\right) \\
\text { where } \mathbf{P} & =\text { rise of internal pressure } \\
\mathbf{C} & =\text { constant of the material } \\
\mathbf{t} & =\text { thickness of the wall of the shell } \\
\mathbf{r} & =\text { original radius } \\
\lambda & =\text { degree of expansion, i.e., } \frac{\mathbf{r}^{\prime}}{\mathrm{r}} \text { where } \mathbf{r}^{\prime}=\text { radius when }
\end{aligned}
$$

This formula must not be applied rigidly to tissue such as lung or to the irregularly shaped spaces of emphysema, but it serves as a guide to the physical principles involved. First, and most obvious, it follows from the inverted relationship of pressure to radius that an emphysematous space, being larger than the normal air spaces, is weakened and will tend to expand to a larger degree with respiration. Secondly, once expansion is started, it progressively requires a diminishing expanding force; the larger the degree of expansion, the more attenuated, and therefore weaker, becomes the wall of the space. Material having a high degree of elasticity has been considered in the formula, and it is unlikely that lung tissue is as elastic, in which case enlargement might become permanent after a smaller degree of expansion. Thus, as a principle in emphysema and one which we have not seen previously considered, we put forward the view that emphysematous spaces may be expected to alter more in size with the pressure changes of breathing than the normal air spaces. This is an attribute of their larger size, no structural reinforcement of their walls occurring to compensate for their pathological dilatation. A non-valvular constriction in the airway leading to emphysematous spaces would have the effect of limiting the quantity of air entering the spaces on inspiration and diminishing that leaving on expiration. As compared with similar spaces having an unrestricted airway, the volume changes with respiration would be less in those with bronchiolar narrowing. Mead, Lindgren, and Gaensler (1955) have shown in experimental animals with one lung throttled and the other with unthrottled airways that, when the rate of ventilation is high, the throttled lung hardly alters in volume throughout all phases of respiration. On such evidence, if $\stackrel{\vec{F}}{\stackrel{5}{9}}$ breathing gives rise to forces capable of causing permanent enlargement of spaces, forces which for one reason or another they are unable to withstand, then narrowing of the bronchioles to such spaces could protect them from continued expansion. Gordon (1944) and Lancet $(1955,1956)$ have even suggested that emphysema is a disease involving those parts of a lung whose airway is normal, and not the parts with narrowed bronchioles, the assumption being that the unobstructed parts have to accept an increased proportion of the total volume of air respired.

EFFECT ON LUNG OF Prolonged HyperinflaTION.-Some of the foregoing conclusions presuppose that respiratory bronchioles are no more vulnerable to the effects of hyperinflation than other structures. We have no direct evidence to support this in the adult, but, in respect of the infant lung, such evidence is available.

A truly obstructive and sometimes chronic emphysema develops in the congenital type of lobar emphysema. Moreover, this condition usually occurs without the infective complications that are the rule with lobar obstruction fron acquired causes. The congenital disease most fre quently involves an upper or the right middle lobe and expansion progressively occurs until the affected lobe occupies the major part of the thoracic space. The cause of the hyperinflation varies; valvular mucosal flaps, weakness of the walls of the bronchi due to the absence of cartilage, and pressure on the bronchi from aberrant vessels have all been reported. We have examined material from two unpublished examples of the condition, in children aged 3 weeks and $5 \frac{1}{2}$ weeks. To determine the changes in structure caused by the marked hyperinflation, tissue from the two emphysematous lobes was examined in serial histological sections. In neither lobe is expansion of the tissue associated with the disruption of intervening airspace walls to form large or abnormal cavities in the lung tissue, and, although overexpanded, the general structure remains intact. The dilatation involves equally alveolar ducts, respiratory and non-respiratory bronchioles (Fig 18). Engel (1947) gives measurements of the diameters of normal terminal bronchioles at various ages of childhood, from which we calculate that in our material these structures are increased in calibre between two and two and a half times. The respiratory systems in these lobes correspond in size, but not in development, with those of a child slightly over 10 years of age. It is probably fair to conclude that, at least as far as the infant 


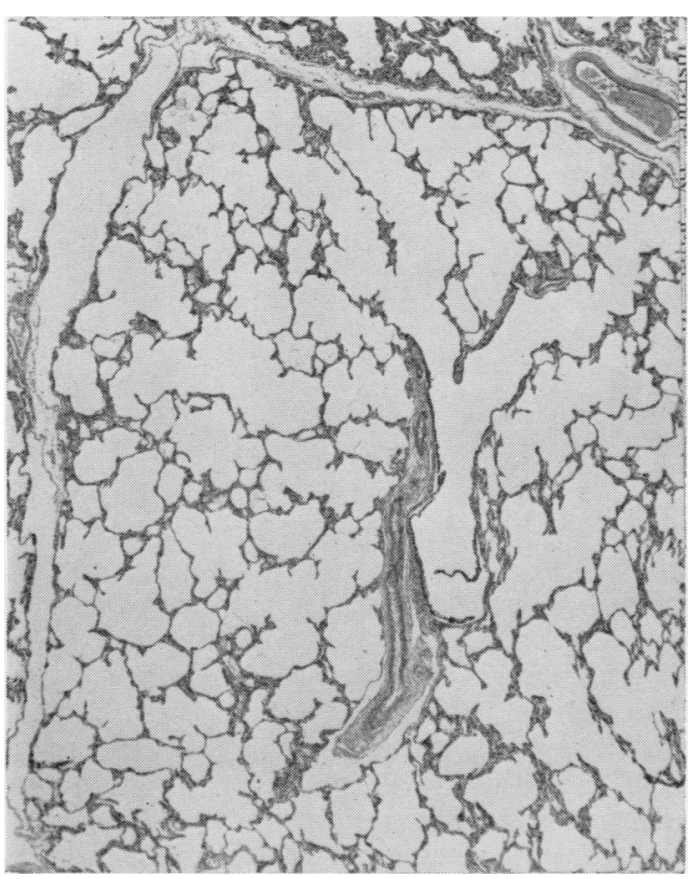

FIG. 18.-Congenital unilobular emphysema. $\times 20$. Child aged 3 weeks. Hyperexpansion of all respiratory structures, respiratory bronchioles no more affected than any other part. No tissue destruction.

lung is concerned, there is no evidence that the respiratory bronchioles are more likely than any other part of the lung tissue to become expanded and damaged when hyperinflation is prolonged. These examples also demonstrate that normal tissues can withstand an extreme degree of hyperinflation without undergoing disruption. This evidence supports the contention that the form of emphysema which we have called centrilobular emphysema is dependent on local inflammatory changes.

\section{SUMmary}

Hypertrophic, i.e., large lung, emphysema can be divided into two forms: one involves the lungs as a whole, generalized emphysema, while the other, in addition to having general emphysema, is complicated by emphysema which particularly affects individual lobules. The lobular lesions start in the centres of the lobules, and for this type the name centrilobular emphysema is proposed. These different forms of emphysema depend for their distinction upon lungs being fixed in an expanded position before examination, and failure to adopt such methods may have hampered the recognition of the centrilobular form.

One hundred and forty lungs with hypertrophic emphysema have been examined and 75 showed the centrilobular form.

The enlarged centrilobular spaces are distal orders of respiratory bronchioles which form clusters of spaces communicating with one another. Alveolar ducts, saccules, and atria surround the clusters, open into them and separate them from the septa which bound the lobule.

All lungs with centrilobular emphysema have chronic bronchiolitis, and the inflammatory changes extend distally to the level where emphysematous expansion occurs. Narrowing of the bronchioles was present in $60 \%$ of lesions but was severe in only $12 \%$. Dilated or normal airways led to the emphysematous cavities in the remaining $40 \%$.

Centrilobular emphysema results from inflammation of respiratory bronchioles, the proximal orders being ensheathed by organized exudate and thickened, the distal order weakened and ruptured to form the emphysematous spaces. The emphysema is not regarded as primarily a consequence of partial obstruction in the airway. The well-established fact that when an elastic sphere expands its walls become weaker is put forward as the explanation of progressive enlargement of emphysematous spaces.

We wish to thank Dr. W. W. Mapleson for his help in explaining the principles involved in the expansion of elastic structures. The photographs are by $\mathrm{Mr}$. J. P. Napper and the diagrams by Miss J. Williams.

REFERENCES

Dayman, H. (1951). J. clin. Invest., 30, 1175.

Engel, S. (1947). The Child's Lung, p. 294, Arnold, London.

Fry, D. L., Ebert, R. V., Stead, W. W., and Brown, C. C. (1954). Amer. J. Med., 16, 80 .

Gordon, I. (1944). Dis. Chest, 10, 180

Gough, J. (1952). Proc. roy. Soc. Med., 45, 576

Green, A. E., and Shield, R. T. (1950). Proc. roy. Soc., A202, 407.

Heppleston, A. G. (1953). J. Path. Bact., 66, 235.

Laennec, R. T. H. (1819). De l'Auscultation Médiate, Vol. 1, p. 221. Paris.

Lambert, M. W. (1955). J. Path. Bact., 70, 311.

Lancet (1955), 2, 810, Annotation. (1956), 1, 30, 810, Annotation.

McAdams, A. J. (1955). Amer.J. Med., 19, 314.

McIlroy, M. B., and Christie, R. V. (1954). Clin. Sci., 13, 147.

McLean, K. H. (1956). Aust. Ann. Med., 5, 73.

Mead J., Lindgren, I., and Gaensler, E. A. (1955). J. clin. Invest., 34, 1005 .

Miller, W. S. (1947). The Lung, 2nd ed. Thomas, Springfield, Illinois. Opie, E. L., Blake, F. G., Small, J. C., and Rivers, T. M. (1921). Epidemic Respiratory Disease, Kimpton, London.

Rokitansky, C. (1852). A Manual of Pathological Anatomy, Vol. 4, translated from the German by George Day, Sydenham Society, London.

Spain, D. M., and Kaufman, G. (1953). Amer. Rev. Tuberc., 68, 24.

Villemin, J. A. (1866). Arch. gén. Méd., 6 ser, 8, 566.

Winternitz, M. C. (1920). Pathology of War Gas Poisoning. Yale University Press, New Haven. 